\title{
INTERACTION BETWEEN HYDROGEN MOLECULES AND A CLOSED NANOTUBE
}

\author{
Egor Tarasov ${ }^{1}$, and Yulia Khudobina ${ }^{1, *}$ \\ ${ }^{1}$ National Research Tomsk Polytechnic University, 634050 Tomsk, Russia
}

\begin{abstract}
The present paper assesses the state of low-energy molecules in the vicinity of the crystal structure of a closed nanotube. It is proposed to use the continuum description of the impact energy from carbon graphene structures. In this approach, a closed tube consists of an open part and two fullerene hemispheres. Calculations revealed that adsorption of gas molecules by surface crystals is not the case of capturing by a part of the nano-object surface, but that of involvement of molecules in a complex orbital motion around the particle.
\end{abstract}

\section{Introduction}

Leaving aside the problem of gas filtration through open nanotubes, which has been the subject for a significant amount of research [1-6], in this paper, we consider a closed nanotube and associated sorption motions of molecules. The results of the comparative analysis of methane sorption by three different types of carbon nano-porous media (nanotubes, carbon fibre and silicon carbide) are given in the work [7]. In general, grapheme-like structures cause considerable interest [8-14] and for the purpose of studying them, classical approaches of molecular [15-28] and wave dynamics [29-31] are applied.

A nanotube can be regarded as a closed and twisted graphene plate. The hexagonal graphene grid is composed of regular hexagons, so that, if in the centre of each hexagonal element we place a point an join it to the vertices, we get a set of equilateral triangles with sides of $0.142 \mathrm{~nm}$. The positions of nodes in the hexagonal grid are controlled by C-C bonds, the same as in the crystalline structure of diamond. But there are large tubes containing thousands of nodes in the crystalline lattice, as well as systems of nanotubes, including about a million carbon atoms. In such cases, it is advisable to use the continual approach.

\section{Continual tube model}

In order to realize the continual approach, the LJ-potential preliminarily used here must be modified in such a way that, when performing continual integration over the surface of the 2D-material, we could obtain a convergent value of the integral action. The above mentioned modification may be the following [8]:

\footnotetext{
*Corresponding author: hudobina@mail2000.ru
} 


$$
d U(\rho)=4 q \varepsilon\left(\frac{\sigma}{\rho}\right) \operatorname{th}\left[\left(\frac{\sigma}{\rho}\right)^{11}-\left(\frac{\sigma}{\rho}\right)^{5}\right] d s
$$

here $\rho$ is the distance between the centre of the test molecule and the centre of the unit area on the surface of the 2D-material, $q$ is density of energy distribution on the surface, $d s$ is the elementary area on the tube surface. For a flat or a cylindrical grapheme structure it is easy to find that $q \approx 28 \mathrm{~nm}^{-2}$. Naturally, introducing cylindrical coordinates and integrating (1) over the side surface of the open nanotube, we obtain:

$$
U(r, z)=4 \varepsilon a q \int_{0}^{2 \pi} \int_{0}^{\mathrm{h}}\left(\frac{\sigma}{\rho}\right) \operatorname{th}\left[\left(\frac{\sigma}{\rho}\right)^{11}-\left(\frac{\sigma}{\rho}\right)^{5}\right] d \varphi^{\prime} d z^{\prime} .
$$

Moreover $\rho=\sqrt{r^{2}+a^{2}-2 \operatorname{arcos} \varphi^{\prime}+\left(z-z^{\prime}\right)^{2}}, a$ is the radius of the nanotube and $h$ is its length. Double integration in (2) can be performed numerically, for each of the integrals using in series the trapezoidal rule.

When integration in (2) is completed, the test molecule velocity can be found from the energy integral:

$$
\frac{m v^{2}}{2}+U=\frac{m v_{0}^{2}}{2}+U_{0}
$$

Or as a result of a numerical solution of the fundamental equation of dynamics:

$$
m \frac{d \vec{v}}{d t}=-\operatorname{grad} U
$$

To integrate this equation it is quite useful to apply the standard version of the Runge-Kutta scheme of the fourth-order accuracy.

\section{Calculation results}

Globally, in interactions of molecules with nanoscale structures, and even macroscopic bodies, it is possible to identify the mode of rapid interaction and the sorption mode. All the results presented here relate to the latter case. Molecules having high energy either move through an open tube, or get reflected. Therefore, we consider interactions of low-energy molecules with tubes. Let us place the origin of the Cartesian coordinate system on the tube axis in the very middle of it, so that its left edge is determined by the coordinate $z=-5 \mathrm{~nm}$ and the right one - by $z=5 \mathrm{~nm}$. We run the hydrogen molecule in the plane $z_{0}=4$, i.e. almost to the edge of the tube, from the position $x_{0}=2.8 r, y_{0}=0$. In this case, its primary velocity components are: $u_{0}=125 \mathrm{~m} / \mathrm{s}, v_{0}=37.5 \mathrm{~m} / \mathrm{s}, w_{0}=0$. 

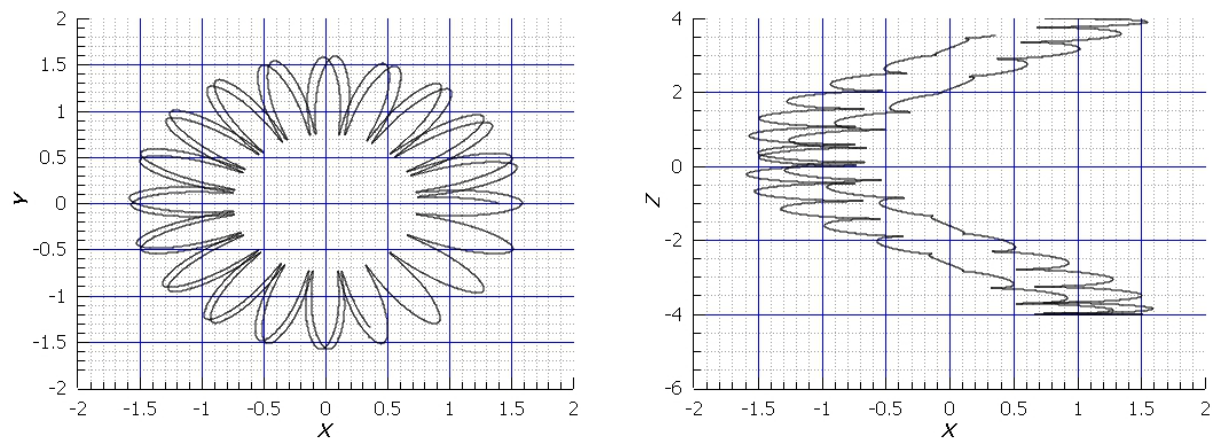

Fig. 1. Projected paths of hydrogen molecule in $x y$ and $x z$ plane for tube of $l=10 \mathrm{~nm}, r=0.5 \mathrm{~nm}$.
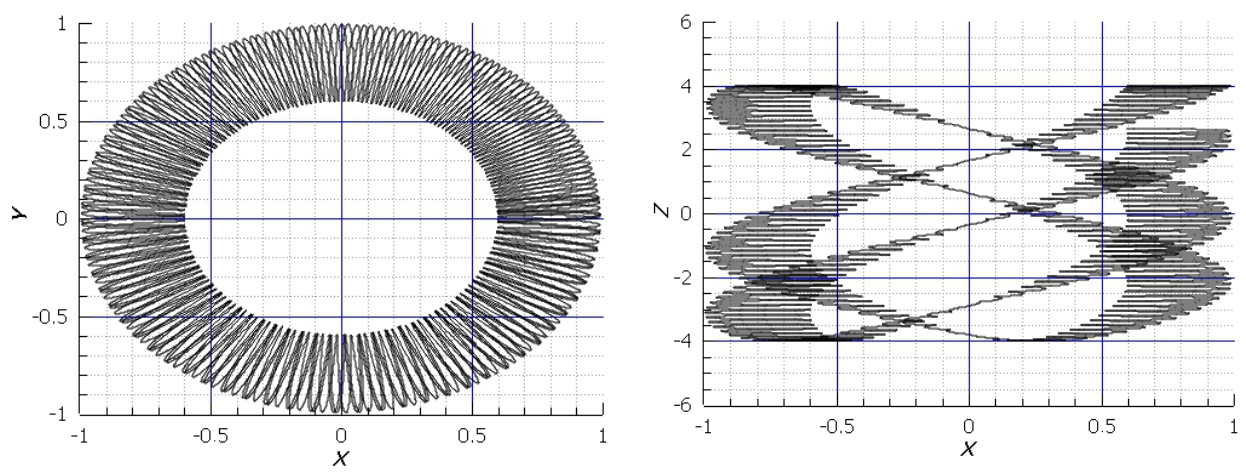

Fig. 2. Projected paths of hydrogen molecule in $x y$ and $x z$ plane for tube of $l=10 \mathrm{~nm}, r=0.35 \mathrm{~nm}$.

Since the smoothed tube is an ideal object and the total energy of the molecule remains constant, the trajectories presented above turned out to be ideal too. The movement in the $x y$ plane is defined by two modes of vibration: the basic mode is associated with circular motion and the radar frequency is determined by the forces of attraction and repulsion. Another vibration is realized along the length of the tube. The frequency of this oscillation is caused by the asymmetric influences of the tube's parts. If at any time point the molecule is at the right end of the tube, the long-range attractive forces directed to the mass centre of the tube make it return to the left end, etc. Fluctuations of a higher frequency presented in the $x y$ plane are generated by the same type of movements during which the molecule moves from the repulsion zone to the attraction area and vice versa.

Thus, in the nature of motion it is possible to identify one frequency associated with the revolution of the molecule around the axis of the tube, another one - with longitudinal movements (along the axis of the tube) and the third one - with radial vibrations of the molecule.

The performed calculations allow evaluating the sorption amount, knowing which, in turn, it is possible to find the associated mass composed of low-energy molecules. The suggested numerical model also allows finding the limiting energy, exceeding which provides the molecule with a way out of the gravitational field of the nanoparticle. From the values of maximum energy in the axes "particle energy - molecule energy" it is easy to construct a sorption curve separating the two global modes of interaction between molecules and particles. Calculations show that adsorption of gas molecules by surface crystals is not the case of holding them on the fragment of the surface, but that of involving them in a complex orbital motion around the particle. 


\section{Acknowledgments}

This paper was written within the frame of Competitiveness Improvement Program of Tomsk State University.

\section{References}

1. D. Mattia, H. Leese, K.P. Lee, J. Membrane Sc. 475 (2015)

2. A. Surapathi, H. Chen, E. Marand, J.K. Johnson, Z. Sedlakova, J. Membrane Sc. 429 (2013)

3. D. Zhao, J. Ren, H. Li, X. Li, M. Deng, J. Membrane Sc. 467 (2014)

4. A.L. Ahmad, Z.A. Jawad, S.C. Low, S.H.S. Zein, J. Membrane Sc. 451 (2014)

5. N. Gilani, J. Towfighi, A. Rashidi, T. Mohammadi, M.R. Omidkhah, A. Sadeghian J. Appl. Surf. Sc. 270 (2013)

6. Y. Zhao, B.T. Jung, L. Ansaloni, W.S. Winston Ho, J. Membrane Sc. 459 (2014)

7. L. Liu, D. Nicholson, S.K. Bhatia, J. Ch. Eng. Sc. 121 (2015)

8. K.A. Krylova, Y.A. Baimova, S.V. Dmitriev, R.R. Mulyukov, Phys. Sol. St. 58 (2016)

9. A.V. Savin, E.A. Korznikova, S.V. Dmitriev, Phys. Sol. St. 57 (2015)

10. K.A. Bukreeva, R.I. Babicheva, S.V. Dmitriev, K. Zhou, R.R. Mulyukov, A.I. Potekaev, Russ. Phys. J. 57 (2014)

11. J.A. Baimova, B. Liu, S.V. Dmitriev, N. Srikanth, K. Zhou, Phys. Chem. Chem. Phys. $16(2014)$

12. E.A. Korznikova, S.V. Dmitriev, J. of Phys. D: Appl. Phys. 47 (2014)

13. E.A. Korznikova, S.Y. Fomin, S.V. Dmitriev, Mat. Sc. Forum 845 (2016)

14. J.A. Baimova, S.V. Dmitriev, Mat. Sc. Forum 838-839 (2016)

15. A.I. Potekaev, M.A. Bubenchikov, Russ. Phys. J. 54 (2011)

16. M.A. Bubenchikov, Russ. Phys. J. 54 (2011)

17. M.A. Bubenchikov, A.I. Potekaev, A.M. Bubenchikov, Russ. Phys. J. 56 (2013)

18. M.A. Bubenchikov, A.I. Potekaev, A.M. Bubenchikov, Russ. Phys. J. 56 (2013)

19. A.I. Potekaev, A.M. Bubenchikov, M.A. Bubenchikov, Russ. Phys. J. 55 (2013)

20. M.A. Bubenchikov, A.I. Potekaev, A.M. Bubenchikov, O.V. Usenko, A.V. Ukolov, IOP Conf. Series: Mat. Sc. Eng. 87, 1 (2015)

21. A. M. Bubenchikov, M.A. Bubenchikov, O.V. Matvienko, E. A. Tarasov, O.V. Usenko, AIP Conf. Proc. 1698 (2016)

22. V.Ya. Rudyak, S.L. Krasnolutskii, D.A. Ivanov, J. Dok. Phys. 57 (2012)

23. V.Ya. Rudyak, A.A. Belkin, V.V. Egorov, D.A. Ivanov, Int. J. Multiphys. 5 (2011)

24. V.Ya. Rudyak, S.L. Krasnolutskii, D.A. Ivanov, J. Microfl. Nanofl. 11 (2011)

25. V.Ya. Rudyak, S.N. Dubtsov, A.M. Baklanov, Tech. Phys. Lett. 34 (2008)

26. V.Ya. Rudyak, S.L. Krasnolutskii, E.N. Ivashchenko, J. Eng. Phys. Thermoph. 81 (2008)

27. V.Ya. Rudyak, J. VDI-Berichte 1803 (2003)

28. V.Ya. Rudyak, A.A. Belkin, Tech. Phys. Lett. 29 (2003)

29. A.M. Bubenchikov, M.A. Bubenchikov, A.I. Potekaev, E.E. Libin, Yu.P. Khudobina, Russ. Phys. J. 57 (2014)

30. A.M. Bubenchikov, M.A. Bubenchikov, A.I. Potekaev, E.E. Libin, Yu.P. Khudobina, Rus. Phys. J. 58 (2015)

30. M. A. Bubenchikov, A. M. Bubenchikov, O. V. Usenko, V. A. Poteryaeva, S. Jambaa, EPJ Web Conf. 110 (2016) 